\title{
Analisis Usability Pada Website Si-Prestasi dengan Metode USE Questionare
}

\author{
Agus Dwi Milniadi *, Yudha Alif Auliya ** \\ Faculty of Computer Science, University of Jember \\ *agusdwimill@gmail.com,**yudha.alif@unej.ac.id
}

\begin{abstract}
Web technology is growing rapidly, with today's website being a role to improve effectiveness, the design of the web can be said to be good when it meets usability aspects for testing the products, which are compatible with the manufacturing and easier access to the site. One of the implementations of the effectiveness of website technology is the implementation of the website to assist with learning teaching at the covid-19 pandemic. Nganjuk district will maintain it by creating an e-learning based website called $\mathrm{Si}$-Prestasi. But in the user data found on the si-prestasi website, there is a user decline from the Si-Prestasi website. In January 2021, student users reached 731,621 and in April 2021 to 187,590 times and teacher users, 3,658 times opened the applications for their accomplishments, and in April 2021 down to 11,612 times. Thus the study aims to analyze Culinaire's usability system by referring to the 5 aspects of usability: learnability, efficiency, memorability, errors, and satisfaction. The results of this research demonstrate that the aspects of learnability, efficiency, memorability, and satisfaction are at a good category value and the error aspect falls insufficient category. Therefore, improvements need to be made to optimize the website and improve on the server si-prestasi websites.
\end{abstract}

Keyword: Usability, Si-Prestasi, Website, e-learning, Nganjuk

\section{Introduction}

Perkembangan teknologi dan komunikasi sekarang sedang berkembang pesat. Kebutuhan mendasar untuk mendukung kinerja dalam suatu institusi, organisasi perlu adanya bantuan dari teknologi informasi. Peran teknologi informasi juga sebagai sarana untuk mengingkatkan proses bisnis maupun evektifitas suatu instistusi maupun organisasi. Perkembangan teknologi informasi yang sedang berkembang salah satunya adalah teknologi website. Dikutip dari Sibero, website adalah suatu sistem yang berkaitan dengan dokumen digunakan sebagai media untuk menampilkan teks, gambar, multimedia, dan lainnya pada jaringan internet [1]. Pengertian lain dari Kustiyahningsih dan Devie, website merupakan salah satu layanan yang didapat oleh pemakai komputer yang terhubung dengan fasilitas hypertext untuk menampilkan data berupa teks, gambar, suara, animasi dan multimedia lainnya [2]. Berdasarkan kedua penjelasan tersebut website merupakan sebuah sebuah media yang ada di dalam internet yang memiliki fasilitas hypertext untuk menampilkan data yang didalamnya terdapat dokumen berupa teks, gambar, suara serta browser untuk mengaksesnya. Pengembangan website sekarang bukan hanya menjadi suatu penyedia informasi saja, namun website sekarang sudah dapat dikembangkan menjadi online shop, sistem pembelajaran dan masih banyak lagi.

Tujuan utama dari website dibuat untuk memudahkan dalam proses memperoleh informasi, mengumpulkan informasi dan menyebarkan informasi. Terdapat permasalahan dalam pengguna website pada umunya yaitu belum dapat mengoperasikan suatu website dengan baik. Faktor yang mempengaruhi hal tersebut adalah aspek user friendly. Aspek user friendly yang menjadi permasalahan oleh pengguna adalah sedikitnya informasi yang ada di dalam website, sehingga pengguna sulit untuk memaksimalkan fitur yang ada di dalam website. Aspek lain yang penting dalam membuat suatu sistem website adalah Usability. Usability adalah sejauh mana sebuah produk atau layanan dapat digunakan pengguna untuk mencapai tujuannya dan seberapa mudah penggunaan dari antarmuka aplikasi tersebut yang dapat menghasilkan nilai kepuasan pengguna dalam menggunakan produk tersebut [3].

Kabupaten Nganjuk merupakan suatu kabupaten di Provinsi Jawa Timur. Kabupaten Nganjuk merupakan suatu Kabupaten yang memiliki suatu website pembelajaran untuk membantu proses belajar mengajar di Kabupaten Nganjuk yaitu Si-Prestasi. Harapan dengan adanya Si-Prestasi adalah untuk membantu proses pembelajaran di Kabupaten Nganjuk bisa lebih terstruktur, menarik dan interaktif melalui fitur materi pembelajaran, evaluasi harian, ujian hingga penugasan siswa. Tujuan website Si-Prestasi memiliki peran penting peran penting untuk mencapai tujuan pembelajaran daring menurut pada Surat Edaran Nomor 15 tahun 2020 Kementrian Pendidikan dan Kebudayaan yaitu memastikan pemenuhan hak peserta didik untuk 
mendapatkan layanan pendidikan selama darurat COVID-19 [4]. Berdasarkan hasil statistik pengguna dari website Si-Prestasi mengalami penurunan pemakaian dari Januari 2021 hingga April 2021, Januari 2021 pengguna Guru mencapai angka 63.658 kali membuka website Si-Prestasi dan pada April 2021 turun menjadi 11.612 kali. Statistik penggunaan website Si-Prestasi dari siswa pada Januari 2021 menunjukkan angka 731.621 dan pada April 2021 menjadi 187.590 kali. Penurunan dari pengguna Guru mencapai 81,75\% dalam 4 bulan dan 74,35\% dari siswa selama 4 bulan. Perlu dilakukan pengujian menggunakan cara USE Questionare untuk mengukur kemudahan dari tingkat kemudahan pada website Si-Prestasi.

Permasalahan utama pada pengguna website Si-Prestasi adalah user interface (UI). UI sangat berperan penting dalam suatu website, karena tingkat kesalahan dalam memanfaatkan fitur website akan menjadi lebih besar jika website tersebut memiliki user interface yang buruk. Hal ini didukung dengan hasil survei yang dilakukan kepada 110 sampel siswa SMP se-Kabupaten Nganjuk yang menunjukkan bahwa kebanyakan bahwa Si-Prestasi yaitu kurang responsive terhadap mobile, tidak adanya notifikasi dalam website dan tidak diberikan kemudahan dalam pengiriman tugas. Permasalahan yang dialami oleh siswa tersebut mengacu pada ketiga aspek usability yaitu efisiensi, efeksivitas dan kepuasan.

Proses penentuan metode penelitian, responden, dan cara pengukuran peneliti merujuk pada penelitian sebelumnya, yaitu berdasarkan hasil penelitian yang dilakukan oleh Kevin dkk yang berjudul Analisis Dan Perbaikan Usability Aplikasi Mobile KAI Access Dengan Metode Usability Testing Dan Use Questionnaire, bahwa pengujian menggunakan metode USE Questionnare yang disimpulkan bahwa penelitian masih membutuhkan responden yang banyak agar mendapatkan hasil yang akurat [5]. Penelitian lain yang dilakukan oleh Edi Suhardi R dan Dyah Vitaloca yang berjudul Analisis Usabilitas Menggunakan Use Questionnaire Pada Sistem Informasi Smk Negeri 3 Makassar dapat ditarik kesimpulan bahwa pengujian aspek usability dapat di peroleh dari 4 variabel yaitu usefulness, ease of use, ease of learning dan satisfaction dapat menguji sistem dengan baik [6]. Penelitian selanjutnya yang dilakukan oleh Dedi Rianto Rahadi yang berjudul Pengukuran Usability Sistem Menggunakan Use Questionnaire Pada Aplikasi Android dalam penelitian ini menggunakan USE Qurstionnare dengan mepertimbangkan 4 variabel usability tetapi pengujian ini menggunakan penilaian skala linkert [7].

Tujuan pengujian website Si-Prestasi yaitu untuk mengukur tingkat usability dari website Si-Prestasi. Berdasarkan 3 penelitian sejenis sebelumnya, pengujian ini akan mudah dicapai dengan menggunakan metode USE Questionare dan diukur menggunakan model skala linkert dan akan diambil beberapa kategori poin seperti sangat setuju hingga ke sangat tidak setuju. Selain itu peneliti menambah jumlah responden untuk mendapatkan hasil yang lebih akurat. Peneliti disini melibatkan 50 siswa sebagai responden yaitu pengguna Si-Prestasi yang akan melakukan uji coba langsung terhadap kualitas Si Prestasi poin yang awalnya sangat setuju ke sangat tidak setuju yang disesuaikan menjadi sangat mudah sekali hingga kurang mudah sekali.

\section{Research Method}

Populasi adalah wilayah yang terdiri dari objek/subjek yang mempunyai kualitas dan karakter tertentu dan sudah ditetapkan oleh peneliti untuk dipelajari lalu kemudian ditarik kesimpulannya [8]. Sasaran utama pengguna aplikasi ini adalah siswa SMP se Kabupaten Nganjuk, namun dalam penelitian ini akan dilakukan pada Sekolah SMP se-Kecamatan Nganjuk sebagai sampel. Jumlah total SMP di Kecamatan Nganjuk adalah 7 sekolah yan akan diwakilkan oleh 50 siswa. Hal ini diberlakukan karena sebagai pengguna Si-Prestasi terbanyak masih berada di wilayah Kecamatan Nganjuk.

Metode pengumpulan data dilakukan dengan metode angket/kuesioner untuk mendapatkan data. Menurut Sugiyono (1999) Skala Likert digunakan untuk mengukur sikap, pendapat, dan persepsi seseorang atau sekelompok orang tentang fenomena sosial yang merupakan skala kontinum bipolar, pada ujung sebelah kiri (angka rendah) menggambarkan suatu jawaban yang bersifat negatif [9]. Data yang akan ditujukan pada responden akan menggunakan skala 1 s/d 5 ditunjukkan pada tabel 1 sebagai berikut:

Tabel 1. Instrumen Pengukuran Skala Linkert

\begin{tabular}{cccccc}
\hline PK & KMS & KM & CM & M & SM \\
\hline Nilai & 1 & 2 & 3 & 4 & 5 \\
\hline
\end{tabular}

Metode penelitian yang digunakan dalam penelitian ini dapat dilihat pada gambar 1 . 


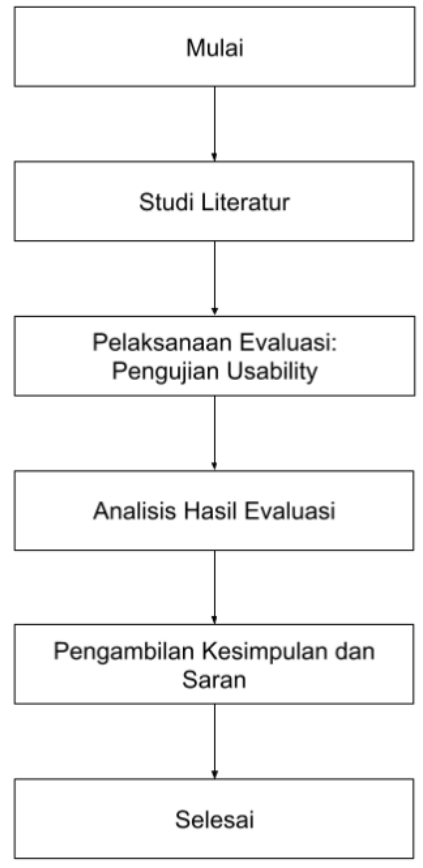

Gambar 1. Diagram Alir Penelitian

Studi Literatur adalah tahapan untuk mendukung penelitian yang telah terdahulu. Sumber studi literatur dapat diambil dari buku, jurnal yang terkait usability testing dan USE Questionare. Pelaksanaan evalusi menggunakan metode USE Questionare. Pada tahap ini dalam website Si-Prestasi hal yang perlu dipersiapkan yaitu penentuan yang akan dijadikan pengujian penelitian. Tahapan selanjutnya yang dilakukan adalah dilakukan penyebaran kuesioner kepada user untuk menggali lebih dalam kenyamanan user dalam penggunaan website Si-Prestasi. Tahap berikutnya setelah evaluasi telah dilaksanakan, peneliti nantinya akan menganalisis data-data yang dikumplkan dari user melalui evaluasi usability. Parameter pengukuran yang akan digunakan adalah aspek kebergunaan (Usefulness), kemudahan penggunaan (Ease of Use), kemudahan mempelajari (Ease of Learning), serta kepuasan pengguna (Satisfaction) [10]. Tahapan ini akan dilakukan penarikan kesimpulan berdasarkan hasil analisis data menggunakan pengujian usability yaitu kuesioner. Setelah itu penelitian akan menarik kesimpulaan berupa rekomendasi saran kedepannya untuk website $\mathrm{Si}$ Prestasi.

\section{Result and Analysis}

Sebelum melakukan pengujian nantinya responden yang berasal dari 50 siswa SMP di Kecamatan Nganjuk akan diberikan beberapa tugas untuk mengakses website Si-Prestasi. Tugas ini dilakukan karena sebagai 'sarana interaksi' dalam pengukuran usability [11]. Tugas yang akan diberikan kepada responden adalah:

a. Membuka halaman website Si-Prestasi

b. Melakukan login kedalam system Si-Prestasi

c. Membuka menu ujian

d. Membuka menu latihan soal

e. Keluar dari sistem

Tahapan selanjutnya setelah semua responden menyelesaikan semua tugas, nantinya responden diwajibkan untuk mengisi kuisioner sesuai dengan pengalaman yang telah dilakukan dalam mengakses website Si-Prestasi. Pertanyaan ini nantinya akan mengacu pada lima aspek usability. Aspek yang dinilai dalam kuesioner akan dinilai dalam skala nilai 5 [12]. Kuesioner akan mencakup lima aspek usability testing yaitu learnability, efficiency, memorability, error, dan satisfaction. Jacob Nielson (2003) mengemukakan lima aspek usability yaitu : Learnability, Efficiency, Memorability, Errors, Satisfaction.

Learnability yaitu Kualitas sistem yang menunjukkan apakah sistem mudah untuk dipelajari dan digunakan dalam menyelesaikan tugas tertentu. Efficiency yaitu Cara yang dapat dilakukan sistem untuk 
mendukung pengguna dalam melakukan pekerjaannya, memiliki langkah-langkah yang sederhana untuk mendapatkan hasil yang sama. Memorability yaitu kemampuan sistem untuk mudah diingat, baik dari sisi fitur atau menu-menu yang ada maupun cara pengoperasiannya. Errors yaitu Perlindungan dan pertolongan kepada pengguna terhadap kondisi dan situasi yang tidak diinginkan dan berbahaya ketika mengoperasikan sistem, misalnya: menu help untuk memberi solusi, dan konfirmasi penghapusan berkas. Satisfaction yaitu Menunjuk kepada suatu keadaan dimana pengguna merasa puas setelah menggunakan sistem tersebut karena kemudahan yang dimiliki oleh sistem. Semakin pengguna menyukai suatu sistem, secara implisit mereka merasa puas dengan sistem yang dimaksud. Pertanyaan untuk menguji aspek usability pada website Si-Prestasi selanjutnya dijabarkan dalam bentuk pertanyaan pada Tabel 2 yang mengacu pada learnability, efficiency, memorability, error, dan satisfaction.

Tabel 2. Pertanyaan Aspek Usability

\begin{tabular}{|c|c|c|c|c|c|c|}
\hline \multirow{2}{*}{ No } & \multirow{2}{*}{ Pertanyaan } & \multicolumn{5}{|c|}{ Aspek Usability } \\
\hline & & Learnability & Efficiency & Memorability & Errors & Satisfaction \\
\hline \multicolumn{7}{|c|}{ Aspek Sistem } \\
\hline 1 & $\begin{array}{l}\text { Apakah tampilan website mudah } \\
\text { dioperasikan dengan Laptop? }\end{array}$ & $\mathrm{V}$ & $\mathrm{V}$ & $\mathrm{V}$ & $\mathrm{V}$ & $\mathrm{V}$ \\
\hline 2 & $\begin{array}{l}\text { Apakah tampilan website mudah } \\
\text { digunakan dengan HP? }\end{array}$ & $\mathrm{V}$ & $\mathrm{V}$ & $\mathrm{V}$ & $\mathrm{V}$ & $\mathrm{V}$ \\
\hline 3 & $\begin{array}{c}\text { Apakah website Si-Prestasi mudah } \\
\text { diakses? }\end{array}$ & $\mathrm{V}$ & $\mathrm{V}$ & $\mathrm{V}$ & $\mathrm{V}$ & $\mathrm{V}$ \\
\hline 4 & $\begin{array}{c}\text { Apakah tampilan warna enak } \\
\text { dilihat dan tidak membosankan? }\end{array}$ & V & V & $\mathrm{V}$ & $\mathrm{X}$ & $\mathrm{V}$ \\
\hline \multicolumn{7}{|c|}{ Aspek Pengguna } \\
\hline 5 & $\begin{array}{c}\text { Apakah tampilan website mudah } \\
\text { dikenali? }\end{array}$ & $\mathrm{V}$ & $\mathrm{V}$ & $\mathrm{V}$ & $\mathrm{X}$ & $\mathrm{V}$ \\
\hline 6 & $\begin{array}{c}\text { Apakah nama Si-Prestasi mudah } \\
\text { diingat? }\end{array}$ & $\mathrm{V}$ & $\mathrm{V}$ & $\mathrm{V}$ & $\mathrm{X}$ & $\mathrm{V}$ \\
\hline 7 & $\begin{array}{l}\text { Apakah tulisan dalam website } \\
\text { mudah dibaca? }\end{array}$ & $\mathrm{V}$ & $\mathrm{V}$ & $\mathrm{V}$ & $\mathrm{X}$ & $\mathrm{V}$ \\
\hline 8 & $\begin{array}{l}\text { Apakah mudah untuk mengakses } \\
\text { Si-Preestasi? }\end{array}$ & $\mathrm{V}$ & $\mathrm{V}$ & $\mathrm{V}$ & $\mathrm{V}$ & $\mathrm{V}$ \\
\hline 9 & $\begin{array}{l}\text { Apakah simbol dan icon gambar } \\
\text { mudah dipahami? }\end{array}$ & $\mathrm{V}$ & $\mathrm{V}$ & $\mathrm{V}$ & $\mathrm{V}$ & $\mathrm{V}$ \\
\hline \multicolumn{7}{|c|}{ Aspek Interaksi } \\
\hline 10 & $\begin{array}{l}\text { Apakah mudah mengakses fitur } \\
\text { pengumpulan ujian pada website? }\end{array}$ & $\mathrm{V}$ & $\mathrm{V}$ & $\mathrm{V}$ & $\mathrm{V}$ & $\mathrm{V}$ \\
\hline 11 & $\begin{array}{l}\text { Apakah fitur yang disediakan } \\
\text { sesuai dengan kebutuhan anda? }\end{array}$ & $\mathrm{V}$ & $\mathrm{V}$ & $\mathrm{V}$ & $\mathrm{V}$ & $\mathrm{V}$ \\
\hline 12 & $\begin{array}{c}\text { Apakah fitur ujian online mudah } \\
\text { diakses? }\end{array}$ & $\mathrm{V}$ & $\mathrm{V}$ & $\mathrm{V}$ & $\mathrm{V}$ & $\mathrm{V}$ \\
\hline 13 & $\begin{array}{c}\text { Apakah menu dari website mudah } \\
\text { diingat? }\end{array}$ & $\mathrm{V}$ & $\mathrm{V}$ & $\mathrm{V}$ & $\mathrm{X}$ & $\mathrm{X}$ \\
\hline
\end{tabular}


Instrumen pertanyaan pada table 2 digunakan pada saat pengguna telah membuka website Si-Prestasi. Aspek pertanyaan yang dibuat telah dibuat dengan 3 aspek yang diuji, yaitu aspek sistem, pengguna dan interaksi. Pengujian tersebut ditujukan agar analisis dapat dilihat dari segi sistem, pengguna dan interaksi serta mendapatkan hasil analisa yang akurat.

Tahap selanjutnya yang dilakukan dalam pengujian website Si-Prestasi yaitu penyebaran kuesioner kepada 50 siswa SMP pengguna Si Prestasi, selanjutnya hasil kuesioner akan diolah menggunakan penghitungan dengan skala linkert dengan rentang jawaban Kurang Mudah Sekali hingga Sangat Mudah, dengan kriteria nilai seperti Tabel 3:

Tabel 3. Nilai Skala Linkert

\begin{tabular}{cc}
\hline Skala Jawaban & Nilai \\
\hline Kurang Mudah Sekali & 1 \\
Kurang Mudah & 2 \\
Mudah & 3 \\
Sangat Mudah & 4 \\
Sangat Mudah Sekali & 5 \\
\hline
\end{tabular}

Proses analisis nantinya bertujuan untuk mencari skor ideal yang nantinya akan dimasukkan kedalam rating scale. Dalam mencari nilai skor kriterium yaitu dengan cara menggunakan rumus:

Skor Kriterium = Nilai Skala $\mathrm{x}$ Jumlah Responden

Hasil skor atau nilai tertinggi dalam nilai skala linkert ini adalah 5 dan jumlah responden adalah 50, maka dari itu skor kriterium dapat dirumuskan sebagai Tabel 4 berikut:

\begin{tabular}{cc} 
Tabel 4. Skor Kriterium \\
\hline Rumus & Skala \\
\hline $5 \times 50=250$ & Sangat Baik \\
$4 \times 50=200$ & Baik \\
$3 \times 50=150$ & Cukup \\
$2 \times 50=100$ & Kurang Baik \\
$1 \times 50=50$ & Sangat Kurang Baik
\end{tabular}

Hasil skor kriterium akan dijadikan menjadi skala rasio untuk mengetahui hasil data angket (kuisioner) secara umum dan keseluruhan yang didapat dari penilaian angket (kuisioner) dengan ketentuan sebagai Tabel 5 berikut:

\begin{tabular}{cc}
\multicolumn{2}{c}{ Tabel 1. Rasio Data Linkert } \\
\hline Rumus & Kategori \\
\hline $201-250$ & Sangat Baik \\
$151-200$ & Baik \\
$101-150$ & Cukup \\
$51-100$ & Kurang Baik \\
$0-50$ & Sangat Kurang Baik
\end{tabular}

Hasil pengolahan data linkert pada tabel 5 menghasilkan data nilai Usability yang ada di Tabel 6 berupa hasil kuisioner usability. 
Tabel 2. Hasil Kuesioner Usability

\begin{tabular}{|c|c|c|}
\hline No & Pertanyaan & $\begin{array}{c}\text { Nilai } \\
(\Sigma(\text { Skala Jawaban * Nilai Skala }))\end{array}$ \\
\hline 1 & $\begin{array}{l}\text { Apakah tampilan website mudah } \\
\text { dioperasikan dengan Laptop? }\end{array}$ & 195 \\
\hline 2 & $\begin{array}{c}\text { Apakah tampilan website mudah digunakan } \\
\text { dengan HP? }\end{array}$ & 196 \\
\hline 3 & Apakah website Si-Prestasi mudah diakses? & 133 \\
\hline 4 & $\begin{array}{l}\text { Apakah tampilan warna enak dilihat dan } \\
\text { tidak membosankan? }\end{array}$ & 154 \\
\hline 5 & Apakah tampilan website mudah dikenali? & 165 \\
\hline 6 & Apakah nama Si-Prestasi mudah diingat? & 166 \\
\hline 7 & $\begin{array}{c}\text { Apakah tulisan dalam website mudah } \\
\text { dibaca? }\end{array}$ & 179 \\
\hline 8 & $\begin{array}{c}\text { Apakah mudah untuk mengakses Si- } \\
\text { Preestasi? }\end{array}$ & 140 \\
\hline 9 & $\begin{array}{c}\text { Apakah simbol dan icon gambar mudah } \\
\text { dipahami? }\end{array}$ & 174 \\
\hline 10 & $\begin{array}{l}\text { Apakah mudah mengakses fitur } \\
\text { pengumpulan ujian pada website? }\end{array}$ & 151 \\
\hline 11 & $\begin{array}{c}\text { Apakah fitur yang disediakan sesuai dengan } \\
\text { kebutuhan anda? }\end{array}$ & 155 \\
\hline 12 & Apakah fitur ujian online mudah diakses? & 147 \\
\hline 13 & Apakah menu dari website mudah diingat? & 188 \\
\hline
\end{tabular}

Tabel 6 menunjukkan nilai pemerimaan user atau acceptance terhadap masing-masing aspek penilaian. Hasil analisis dapat dilihat bahwa website dapat mudah dilihat dari laptop maupun handphone ditunjukkan dengan nlai 195 dan 196 dan masuk ke dalam data linkert kategori Baik (sudah berada pada kategori cukup atau nilai tengah). Hubungan antara aspek usability dalam Tabel 2, dapat dikatakan bahwa suatu perangkat lunak dibuat dengan memiliki usability yaitu: Learnability, Efficiency, Memorability, Errors, dan Satisfaction. Hal ini ditunjukan dengan nilai usability pada kelima atribut berikut:

a. Nilai atribut "website mudah dikenali" sebesar 165 (Baik) menunjukkan bahwa website tersebut telah memiliki nilai Learnability

b. Nilai atribut "website mudah dioperasikan di laptop maupun hanphone" sebesar 195 yang menunjukkan bahwa website tersebut telah memiliki nilai Efficiency

c. Nilai atribut "menu website mudah diingat" sebesar 188 (Baik) menunjukkan bahwa website tersebut telah memiliki nilai Memorability

d. Nilai atribut "website mudah diakses" sebesar 133 (Cukup) dan "fitur ujian online mudah diakses" sebesar 147 (Cukup) menunjukkan bahwa website tersebut harus bisa meminimalisir aspek nilai Error

e. Dari keseluruhan nilai berada di nilai (151-200), menunjukkan bahwa website sudah memiliki aspek Statisfaction yang sangat baik.

\section{Conclusion}

Hasil rekap nilai dari aspek Usability menggunakan kuesioner, rata-rata nilai yang diberikan oleh user berada pada nilai (150-200) atau pada kategori Baik sangat mudah dipelajari dan dimengerti oleh pengguna. Aspek yang perlu diperhatikan salah satunya yaitu aspek Error, karena nilai dari aspek Error beberapa masih berada pada kategori nilai Cukup. Kategori pengujian lainnya pada website Si Prestasi menujukkan bahwa website sudah responsive karena dibuktikan juga dengan nilai Usability pada saat digunakan di laptop maupun pondrl yang menunjukkan nilai 195 dan 196 atau dalam kategori Baik. Saran kepada pengambang website Si Prestasi diharapkan dapat memaksimalkan aspek Usability dari Learnability, Efficiency, Memorability, Errors, dan Satisfaction. Dalam website Si Prestasi yang perlu diberikan fokus adalah aspek Errors karena masih banyak terdapat kesulitan akses Si Prestasi yang dirasakan oleh pengguna. Dalam hal ini menambah kecepatan transfer data dari server dan mengoptimalisasi website agar lebih ringan sangat diperlukan untuk meminimalisir Errors.

\section{References}

[1] Kun Zhu; Chenine, M.; Nordstrom, L.; , "ICT Architecture Impact on Wide Area Monitoring and Control Systems' Reliability," Power Delivery, IEEE Transactions on, vol.26, no.4, pp.2801-2808, Oct. 2011 
[2] Alexander F.K Sibero. 2013. Web Programing Power Pack.mediaKom. Yokyakarta

[3] Yeni Kustiyahningsih, Devie Rosa Anamisa, 2011.Pemograman Basis Data Berbasis Web Menggunakan PHP \& MySQL.Graha Ilmu : Yogyakarta.

[4] Nielsen, J., 2000. "Why You Only Need to Test with 5 Users". Diakses pada 10 Juni 2020.

[5] Kemendikbud, 2020. "Surat Edaran Menteri Pendidikan dan Kebudayaan Tentang Pelaksanaan Kebijakan Pendidikan Dalam Masa Darurat Penyebaran Coronavirus”. Diakses pada 15 Juni 2020.

[6] Hadi, K, dkk. 2018. Analisis Dan Perbaikan Usability Aplikasi Mobile KAI Access Dengan Metode Usability Testing Dan Use Questionnaire. Jurnal Pengembangan Teknologi Informasi dan Ilmu Komputer.

[7] Rahman, Edi Suhardi. Vitalocca, Dyah. 2018. Analisis Usabilitas Menggunakan Use Questionnaire Pada Sistem Informasi Smk Negeri 3 Makassar. Jurnal Mekom

[8] Rahadi, D. R. (2014). Pengukuran Usability Sistem Menggunakan Use Questionnaire Pada Aplikasi Android Interface pengguna Android. Jurnal Sistem Informasi, 6(1), 661-671.

[9] Marthasari, G.I. \& Hayatin, N. 2017. "Analisis Usability Terhadap Sistem Lective Gegulang Berbasis USE Questionnaire". Prosiding Seminar Teknologi dan Rekayasa (SENTRA).

[10] Dewi, M.A.C. 2019. "Pengaruh Persepsi Kegunaan, Persepsi Kemudahan, Keamanan Dan Kerahasiaan, Tingkat Kesiapan Teknologi Informasi Dan Kepuasan Pengguna Wajib Pajak Terhadap Intensitas Perilaku Wajib Pajak Dalam Penggunaan E-Filling”. Jurnal Sains, Akuntansi Dan Manajemen (JSAM). Vol. 1(3), pp. 317-367

[11] Sugiyono, 1999, Metode PenelitianBisnis, Penerbit Alfabetabandung

[12] Sastramihardja, H., Hapsari, I.N., Neri, I.A. 2018. "Pengukuran Usability Dengan Sarana Task Model Dalam User Center Software Development". Jurnal Penelitian dan Pengembangan Telekomunikasi Vol. 13, No. 2. Desember 2008.

[13] Wingnjosoebroto, S., Sudiarno, A., Harenda, D. 2009. "Perancangan Interface Prototype Web Berdasarkan Pada Aspek Usability (Studi Kasus: Laboratorium Ergonomi dan Perancangan Sistem Kerja Teknik Industri ITS)". Diakses 20 Juni 2020. 